\title{
Increased UGT1A3 and UGT1A7 Expression is Associated with Pancreatic Cancer
}

\author{
Latif Yilmaz $^{1}$, Ersin Borazan ${ }^{1}$, Turkan Aytekin ${ }^{2 *}$, Ilyas Baskonus ${ }^{1}$, Alper Aytekin ${ }^{1}$, \\ Serdar Oztuzcu ${ }^{3}$, Zehra Bozdag ${ }^{4}$, Ahmet Balik ${ }^{1}$
}

\begin{abstract}
UGT1A play important roles in the glucuronidation of a variety of endogenous and exogenous compounds. UGT1A isoforms are expressed tissue specifically. The aim of this study was to examine the relationship between UGT1A3 and UGT1A7 mRNA expression and pancreatic cancer. Paired healthy and tumor tissue samples of 43 patients with pancreatic cancer were included in this study. UGT1A3 and UGT1A7 mRNA expressions were analyzed by real time-PCR. In the result of study, UGT1A3 and UGT1A7 mRNA expressions were significantly higher in tumor tissue than normal tissue of pancreatic cancer patients $(\mathbf{p}<0.05)$. In addition, high mRNA expression of UGT1A3 and UGT1A7 was significantly associated with larger tumor size $(\mathbf{p}<0.05)$. The data suggested that UGT1A3 and UGT1A7 may play roles in the progression of pancreatic cancer. Consequently, UGT1A3 and UGT1A7 are potential prognostic indicators.
\end{abstract}

Keywords: UGT1A3 - UGT1A7 - expression - pancreatic cancer

Asian Pac J Cancer Prev, 16 (4), 1651-1655

\section{Introduction}

Pancreatic cancer is one of the most lethal human malignancies and the seventh most common cancer (Jemal et al., 2011; Afsar et al., 2014). Data from Asia show pancreatic cancer is a high aggressive malignant tumor and has a low survival rate (Chen et al., 2013; Zahir et al., 2013; Bayoglu et al., 2014; Wang et al., 2014). Pancreatic cancer has high rate of metastases (Canyilmaz et al., 2013). The prognosis of patients with advanced stage pancreatic cancer is much worse than for those with early stage disease. Unfortunately, more than $80 \%$ of pancreatic cancer patients were in an advanced stage when diagnosed (Huang et al., 2009; Liu et al., 2014)

Uridine 5'-diphosphate (UDP) glucuronosyltransferases (UGTs) are an important group of phase II drug metabolism enzymes in humans (Tukey and Strassburg, 2000). The human UDPglucuronosyltransferases (UGTs) are a superfamily of proteins which perform a key process in endobiotic and xenobiotic metabolism (Strassburg et al., 1999a) UGTs catalyze the glucuronidation of many important endogenous compounds such as bilirubin, bile acids, thyroid hormone, and steroid hormones as well as substantial exogenous substrates including many therapeutic drugs, heterocyclic and polycyclic hydrocarbons, and heterocyclic amines, which are known human carcinogens (Vogel et al., 2001; Ockenga et al., 2003; Nakamura et al., 2008).
The UGT enzymes have been divided into two families of proteins termed UGT1 and UGT2, and three subfamilies of proteins termed UGT1A, UGT2A and UGT2B in human beings (Hanioka et al., 2012). The human UGT1A gene locus is located on chromosome 2 q37, which encodes nine functional isoforms (UGT1A1, UGT1A3-UGT1A10) and four pseudogenes (UGT1A2, UGT1A11-UGT1A13) (Gong et al., 2001). These isoforms are expressed tissue specifically and reveal large differences in their expression levels in different tissues (Vogel et al., 2001; Final et al., 2005).

UGT1A1, UGT1A3, UGT1A4, UGT1A6, and UGT1A9 gene transcripts are expressed in liver tissue (Strassburg et al., 1997). UGT1A7, UGT1A8 and UGT1A10 have been shown to be differentially regulated in extrahepatic tissues such as small intestine (Strassburg et al., 2000), biliary (Strassburg et al., 1997), oesophagus (Strassburg et al., 2002a), stomach (Strassburg et al., 1998a), colonic epithelium (Strassburg et al., 1999b), kidney, prostate and breast (Starland-Davenport et al., 2008).

In literature, there have been studies regarding UGT1A7 gene polymorphism in pancreatic cancer (Ockenga et al., 2003; Verlaan et al., 2005; Piepoli et al., 2006), and the association of UGT1A expressions with various cancers, including gastric adenocarcinoma (Strassburg et al., 1998b), colorectal cancer (Wang et al., 2012; Wang et al., 2013), bladder cancer (Izumi et

${ }^{1}$ Department of General Surgery, Faculty of Medicine, University of Gaziantep, ${ }^{2}$ Department of Biology, Faculty of Arts and Sciences, ${ }^{3}$ Department of Medical Biology, Faculty of Medicine, ${ }^{4}$ Department of Pathology, Faculty of Medicine, Gaziantep University, Gaziantep, Turkey*For correspondence: turkanayte@hotmail.com 
al., 2014), and breast cancer (Starland-Davenport et al., 2008). To our knowledge, expression of UGT1A3 and UGT1A7 have not been studied thoroughly in pancreatic cancer and corresponding normal tissues. In our study, we aimed to investigate the association between expression of UGT1A3 and UGT1A7 and pancreatic cancer.

\section{Materials and Methods}

\section{Tissue samples}

All samples were from patients admitted to Gaziantep University Medical Faculty, Department of General Surgery, between November 2012 and February 2014. Paired normal and tumor tissue samples were obtained from 43 patients with pancreatic cancer, including 30 males and 13 females, who had an average age of 61.5 years. None of the patients were treated with chemotherapy, radiation therapy or other biological treatment. All samples were taken after informed consent, according to the declaration of Helsinki. Ethics committee approval required for the study was obtained from the Gaziantep University Medical Faculty Local Ethics Committee. Samples were frozen immediately in liquid nitrogen and stored at $-80^{\circ} \mathrm{C}$ until analysis.

\section{RNA Extraction}

Tissue samples were homogenized in liquid nitrogen. Total RNA was isolated from homogenized tissues using the Qiagen RNA Isolation Kit (Valencia, CA) according to the practical recommendations of manufacturer. Total RNA concentrations were measured by spectrophotometry at 260 and $280 \mathrm{~nm}$ and its quality was assessed by conventional gel electrophoresis. RNA samples were stored in water at $-80^{\circ} \mathrm{C}$ until further use.

\section{cDNA Synthesis}

Reverse transcription of RNA was done in a final volume of $20 \mu \mathrm{l}$ containing $5 \mathrm{X}$ RT-PCR buffer, 10 $\mathrm{mM}$ each deoxynucleotide triphosphate, 40 units $/ \mu \mathrm{L}$ of recombinant RNase inhibitor, 200 unit $/ \mu \mathrm{L}$ reverse transcriptase, $20 \mu \mathrm{M}$ random hexamers and $2 \mu \mathrm{g}$ of total RNA. The samples were incubated at $42^{\circ} \mathrm{C}$ for $60 \mathrm{~min}$, and reverse transcriptase was inactivated by heating at $85^{\circ} \mathrm{C}$ for $5 \mathrm{~min}$ and cooling at $4^{\circ} \mathrm{C}$ for $3 \mathrm{~min}$.

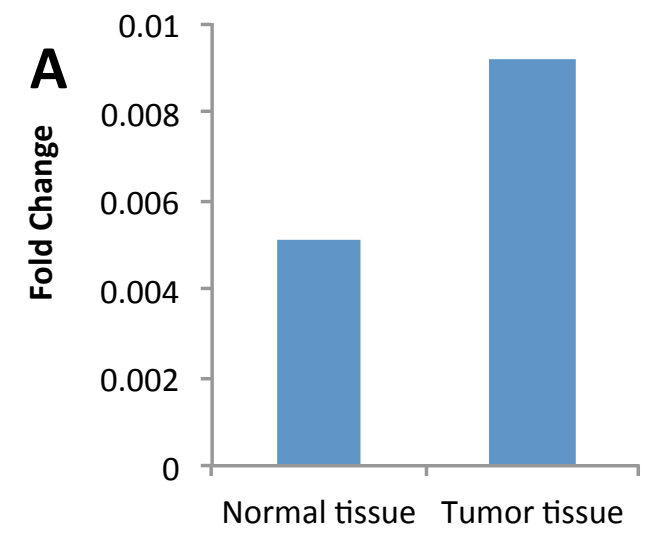

Analysis of UGT1A3 and UGT1A7 mRNA Expression by Real-Time PCR (RT-PCR)

The expression of UGT1A3 and UGT1A7 was examined in tumor and normal pancreatic tissues of the same patient. The mRNA levels of UGT1A3 (sense: 5'- GGATGAATTTGATCGCCATGTG-3', anti-sense: 5'-TGTCATGTGGTCTGAATTGGTT-3'), UGT1A7 (Sense:5'-CCTCTTTCCTATGTCCCCAGA-3', Antisense:5'-CCTCTTTCCTATGTCCCCAGA-3') in relation to the housekeeping gene, $\beta$-actin (ACTB RefSeq Accession no: NM_001101.3), were determined by RealTime PCR. RT- PCR was performed in $50 \mu \mathrm{L}$ of reaction mixture with 50ng cDNA, 400nM of each primer, 25 $\mu \mathrm{L}$ SYBR Green Master Mix and deionized water. RTPCR thermal cycling conditions were as follows: initial denaturation at $95^{\circ} \mathrm{C}$ for $15 \mathrm{~min}$, followed with 40 cycles of $15 \mathrm{~s}$ of $94^{\circ} \mathrm{C}, 30 \mathrm{~s}$ of $55^{\circ} \mathrm{C}, 30 \mathrm{~s}$ of $72^{\circ} \mathrm{C}$ and final extension at $72^{\circ} \mathrm{C}$ for $10 \mathrm{~min}$. Real-time PCR was performed using Rotor Gene 6000 Real-Time PCR Machine (Qiagen $\mathrm{GmbH}$, Hilden, Germany).

\section{Statistical analysis}

SPSS 22.0 software (SPSS, Chicago, USA) was used for statistical analysis. RT-PCR results were expressed using the comparative threshold method (Livak and Schmittgen, 2001). The threshold cycle number (CT) value for UGT1A3 and UGT1A7 was normalized against $\beta$-actin and calculated as $\Delta \mathrm{CT}=\mathrm{CT}_{\mathrm{UGT1A} 3}-\mathrm{CT}_{\beta \text {-actin }}$ and $\Delta \mathrm{CT}=\mathrm{CT}_{\mathrm{UGT1A}}-\mathrm{CT}_{\beta \text {-actin }}$. Relative UGT1A3 and UGT1A7 mRNA expressions were expressed as fold of UGT1A3 and UGT1A7 versus reference: $F=2^{(\Delta C T)}$. All PCR reactions were performed in triplicate in three independent experiments. Data analysis was performed using the RT2 Profiler PCR Array Data Analysis version 3.5 (Qiagen $\mathrm{GmbH}$, Hilden, Germany). This analysis program is based on $2^{-\triangle \triangle C T}$ method for fold change calculations.

Data groups were analyzed using Student's t-test to determine if there were significant differences between normal and cancer tissues. Statistical significance was concluded at $\mathrm{p}<0.05$.

\section{Results}

Total RNA from pancreatic cancer and corresponding

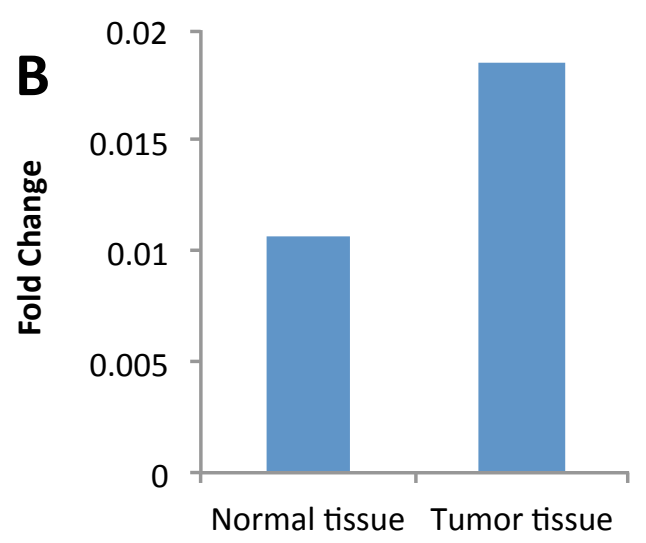

Figure 1. Fold Changes of UGT1A3 (a) and UGT1A7 (b) in Normal and Tumor Tissues of Pancreatic Cancer Patients 
Table 1. UGT1A3 and UGT1A7 mRNA expression levels in Normal and Tumor Tissues of Patients with Pancreatic Cancer

\begin{tabular}{lcccc}
\hline & Mean $\left(2^{-\triangle C t}\right)$ & Variance & df & $\mathrm{p}$ value \\
\hline UGT1A3 & & & & \\
Normal tissue & 0.03 & 0.001 & 42 & $0.04^{*}$ \\
Tumor tissue & 0.09 & 0.064 & & \\
UGT1A7 & & & & \\
Normal tissue & 0.07 & 0.007 & 42 & $0.03^{*}$ \\
Tumor tissue & 0.14 & 0.067 & & \\
\hline *p<0.05 & & & &
\end{tabular}

Table 2. Relationship between Tumor Size and UGT1A3 and UGT1A7 mRNA Expression Levels

\begin{tabular}{lcccc}
\hline & $\begin{array}{c}2^{-\Delta \mathrm{Ct}} \mathrm{N}-\mathrm{T} \\
(\mathrm{UGT} 1 \mathrm{~A} 3)\end{array}$ & $\begin{array}{c}\text { Tumor size } \\
\left(\mathrm{cm}^{2}\right)\end{array}$ & $\begin{array}{c}2^{-\Delta \mathrm{Ct}} \mathrm{N}-\mathrm{T} \\
(\mathrm{UGT} 1 \mathrm{~A} 7)\end{array}$ & $\begin{array}{c}\text { Tumor size } \\
\left(\mathrm{cm}^{2}\right)\end{array}$ \\
\hline Mean & -0.06 & 16.14 & -0.07 & 16.14 \\
Varience & 0.07 & 336.47 & 0.05 & 336.47 \\
df & 42 & & 42 & \\
$\mathrm{p}$ value & $0.00 *$ & & $0.00 *$ & \\
\hline $\mathrm{p}<0.05$ & & &
\end{tabular}

normal tissue was analyzed for the mRNA expressions of UGT1A3 and UGT1A7 by RT-PCR method.

In pancreatic cancer patients, UGT1A3 and UGT1A7 mRNA expressions were increased in tumor tissues compared with the surrounding healthy tissues (Figure 1) These results were statistically significant $(\mathrm{p}<0.05)$ (Table 1).

In this study was investigated relationship between tumor size and the levels of mRNA expression UGT1A3 and the UGT1A7. To determine the relationship, $2^{-\Delta \mathrm{Ct}}$ value of tumor tissue than $2^{-\mathrm{ACt}}$ value of normal tissue was taken away (Livak and Schmittgen, 2001). Tumor sizes were compared to the values $\left(2^{-\Delta \mathrm{Ct}} \mathrm{N}-\mathrm{T}\right)$ for both UGT1A3 and UGT1A7 expressions by using student's t-test. We found that UGT1A3 and UGT1A7 mRNA expressions in tumor tissues were increased tumor size and this was statistically significant $(\mathrm{p}<0.05)$ (Table 2 ).

\section{Discussion}

An important superfamily of proteins that play a role in cellular detoxification and defense are the UDPglucuronosyltransferase, which are expressed in different tissues with xenobiotic contact and have been implicated in chemical carcinogenesis (Strassburg et al., 1999a). Human UGT1A genes are regulated in a tissue-spesific fashion in hepatic and extrahepatic tissues (Strassburg et al., 1998a).

In the present study, we investigated the mRNA expression levels of the UGT1A3 and the UGT1A7 in human pancreatic tissues with cancer and normal. The mRNA levels of the UGT1A3 and the UGT1A7 assigned by RT-PCR using specific primers. For this reason, we determined the UGT1A3 and the UGT1A7 mRNA levels. To our knowledge, this is the first study to examine mRNA expression levels of UGT1A3 and UGT1A7 in pancreatic tumor and normal samples.

The UGT1A3 gene transcript is expressed in liver tissue (Strassburg et al., 1997). The UGT1A7 gene is differentially expressed in the human lung (Guillemette et al., 2000), esophagus (Strassburg et al., 1999a), stomach (Strassburg et al., 1997), small intestine (Strassburg et al., 2000) and colon (Strassburg et al., 1998b; Strassburg et al., 1999b) but is absent from the liver (Strassburg et al., 2001). Ockenga et al. (2003) reported high levels of UGT1A7 mRNA and low levels of UGT1A3 transcripts in normal pancreatic tissue. In the same study, downregulation of the UGT1A3 mRNA was determined in pancreatic adenocarcinoma (Ockenga et al., 2003). In this study, we found that the mRNA expression levels of UGT1A3 and UGT1A7 was significantly increased in tumor tissue compared with normal tissue of pancreatic cancer patients. Strassburg et al. (1998b) showed that UGT1A7 mRNA was up-regulated in gastric adenocarcinoma. Contrary to our result, it was shown to decrease mRNA expression of UGT1A isoforms in adenocarcinoma tissue compared with normal colonic mucosa using immunohistochemical analysis (Wang et al., 2012). In another study conducted with colorectal cancer patients, UGT1A mRNA expressions were significantly reduced in pathological tissues compared with the surrounding healthy tissues harvested together (Wang et al., 2013). UGT1A expression was down-regulated in bladder cancer (Izumi et al., 2014).

Strassburg et al. (2000) reported that the UGT1A isoforms were present in gastrointestinal tissues from individuals but were absent in those from other individuals. Additionally, UGT1A10 mRNA expression levels were correlated with the ethnicity of the donors (Starland-Davenport et al., 2008). Polymorphism leads to different degrees of transcriptional as well as functional alterations, which may decrease UGTs activity and results in pathology of the affected individuals (Wang et al., 2013). Five single nucleotide polymorphisms of the UGT1A7 gene were identified. UGT1A7 gene defining three polymorphic UGT1A7 alleles (UGT1 A7 ${ }^{* 2}$, $\mathrm{UGT}_{1 \mathrm{~A}} 7^{* 3}$ and UGT1A7 ${ }^{* 4}$ ) (Strassburg et al., 2002b). The UGT1A $7^{* 3}$ allele with low mutagen detoxification activity was identified as a risk factor for cancers of the pancreas (Ockenga et al., 2003) and colorectal (Tang et al., 2005). Piepoli et al. (2006) suggested that the frequency of genetic polymorphism in UGT1A7 in pancreatic cancer patients was not different from healthy controls in Italian population. In our study, the UGT1A7 gene polymorphism was not analyzed in normal and tumor tissues of the pancreas. The interindividual differences in the expression may partly result from genetic polymorphism and epigenetic modifications on the promoter or coding region affect the transcriptional activity or mRNA stability (Strassburg et al., 2000; Peters et al., 2003). There are inter-individual differences in the expression of the UGT1A7 (Verlaan et al., 2005). When results of our study compared with the results of studies in different types of cancer, polymorphisms which led to inter-individual variation may be effective in the different of UGT1A3 and UGT1A7 mRNA expression levels.

In addition to genetic polymorphism, the induction by environmental and/or diet would be casual factors of the variability of the UGT expression (Nakamura et al., 2008). Moreover, it was shown that UGT expression 
was restricted to certain cell types or regions in an organ by immunohistochemical studies. For example UGT1A expression has been shown to be restricted to the proximal and distal convoluted tubules, the loops of Henle, and the collecting ducts in kidney (Gaganis et al., 2007).

The differential regulation of UGT1A3 and UGT1A7 mRNA expressions in individual tissues may be the biochemical basis of differences in carcinogen glucuronidation in specific human organs. The UGT1A3 and UGT1A7 mRNA expression differences can create different from each other cytotoxic and genotoxic effects in pancreatic tissue and other tissues.

In the present study, we also demonstrated a positive correlation between the mRNA expression levels of UGT1A3 and UGT1A7 and tumor size in pancreatic cancer. A high expression of UGT1A3 and UGT1A7 was significantly associated with larger tumor size. These findings suggested that UGT1A3 and UGT1A7 may play roles in the progression of pancreatic cancer and may present promising target genes for the diagnosis and treatment of pancreatic cancer. Together, these results indicate that elevated expression of UGT1A3 and UGT1A7 may contribute to tumor growth in pancreatic cancer.

In order to clarify exactly the relationship between UGT1A3 and UGT1A7 genes with pancreatic cancer, protein levels and polymorphic expressions of these genes should be investigated in the future studies. We also think it would be effective to explore the expression levels of transcription factors, which are known to regulate expression of UGT1A3 and UGT1A7.

In conclusion, it is suggest that UGT1A3 and UGT1A7 are involved in the development and progression of pancreatic cancer and may constitute potential targets for novel treatment strategies.

\section{References}

Afsar CU, Gunaldi M, Kum P, et al (2014). Pancreatic carcinoma, thrombosis and mean platelet volume:single center experience from the southeast region of Turkey. Asian Pac J Cancer Prev, 15, 9143-6.

Bayoglu IV, Varol U, Yildiz I, et al (2014). Second-line capecitabine and oxaliplatin combination for gemcitabineresistant advanced pancreatic cancer. Asian Pac J Cancer Prev, 15, 7119-23.

Canyilmaz E, Serdar L, Uslu GH, et al (2013). Evaluation of prognostic factors and survival results in pancreatic carcinomas in Turkey. Asian Pac J Cancer Prev, 14, 6573-8.

Chen WQ, Liang D, Zhang SW, et al (2013). Pancreatic cancer incidence and mortality patterns in china, 2009. Asian Pac J Cancer Prev, 14, 7321-4.

Finel M, Li X, Gardner-Stephen D, et al (2005). Human UDPGlucuronosyltransferase 1A5: identification, expression, and activity. J Pharmacol Exp Ther, 315, 1143-9.

Gaganis P, Miners JO, Brennan JS, Thomas A, Knights KM (2007). Human renal cortical and medullary UDPglucuronosyltransferases (UGTs): immunohistochemical localization of UGT2B 7 and UGT1A enzymes and kinetic characterization of S-naproxen glucuronidation. $J$ Pharmacol Exp Ther, 323, 422-30.

Gong QH, Cho JW, Huang T, et al (2001). Thirteen UDPglucuronosyltransferase genes are encoded at the human
UGT1 gene complex locus. Pharmacogenetics, 11, 357-68. Guillemette C, Ritter JK, Auyeung DJ, Kessler FK, Housman DE (2000). Structural heterogeneity at the UDPglucuronosyltransferase 1 locus: functional consequences of three novel missense mutations in the human UGT1A7 gene. Pharmacogenetics, 10, 629-44.

Hanioka N, Iwabu H, Hanafusa H, Nakada S, Narimatsu S (2012). Expression and Inducibility of UDP-glucuronosyltransferase 1As in MCF-7 human breast carcinoma cells. Basic Clin Pharmacol, 110, 253-8.

Huang WY, Yue L, Qiu WS, et al (2009). Prognostic value of CRM1 in pancreas cancer. Clin Invest Med, 32, 315-21.

Izumi K, Li Y, Ishiguro H, et al (2014). Expression of UDPglucuronosyltransferase 1A in bladder cancer: association with prognosis and regulation by estrogen. Mol Carcinogen, 53, 314-24.

Jemal A, Bray F, Center MM, et al (2011). Global cancer statistics. CA Cancer J Clin, 61, 69-90.

Liu SZ, Chen WQ, Wang N, et al (2014). Dietary factors and risk of pancreatic cancer: a multi-centre case-control study in China. Asian Pac J Cancer Prev, 14,7947-50.

Livak KJ, Schmittgen TD (2001). Analysis of relative gene expression data using real-time quantitative PCR and the 2(-Delta Delta C(T)) method. Methods, 25, 402-8.

Nakamura A, Nakajima M, Yamanaka H, Fujiwara R, Yokoi T (2008). Expression of UGT1A and UGT2B mRNA in human normal tissues and various cell lines. Drug Metab Dispos, 36, 1461-4.

Ockenga J, Vogel A, Teich N, et al (2003). UDP Glucuronosyltransferase (UGT1A7) gene polymorphisms increase the risk of chronic pancreatitis and pancreatic cancer. Gastroenterol, 124, 1802-8.

Peters WH, te Morsche RH, Roelofs HM (2003). Combined polymorphisms in UDP-glucuronosyltransferases 1A1 and 1A6: implications for patients with gilbert's syndrome. $J$ Hepatol, 38, 3-8.

Piepoli A, Gentile A, Valvano MR, et al (2006). Lack of association between UGT1A7, UGT1A9, ARP, SPINK1 and CFTR gene polymorphisms and pancreatic cancer in Italian patients. World J Gastroenterol, 12, 6343-8.

Starlard-Davenport A, Lyn-Cook B, Radominska-Pandya A (2008). Identification of UDP-glucuronosyltransferase $1 \mathrm{~A} 10$ in non-malignant and malignant human breast tissues. Steroids, 73, 611-20.

Strassburg CP, Barut A, Obermayer-Straub P, et al (2001). Identification of cyclosporine A and tacrolimus glucuronidation in human liver and the extrahepatic gastrointestinal tract by a differentially expressed UDPglucuronosyltransferase:UGT2B7. J Hepatol, 34, 865-72.

Strassburg CP, Kneip S, Topp J, et al (2000). Polymorphic gene expression and interindividual variation of UDPglucuronosyltransferase activity in human small intestine. J Biol Chem, 275, 36164-71.

Strassburg CP, Manns MP, Tukey RH (1998). Expression of the UDP-glucuronosyltransferase 1A locus in human colon. Identification and characterization of the novel extrahepatic UGT1A8. J Biol Chem, 273, 8719-26.

Strassburg CP, Nguyen N, Manns MP, Tukey RH (1998b). Polymorphic Expression of the UDP-glucuronosyltransferase UGT1A gene locus in human gastric epithelium. $\mathrm{Mol}$ Pharmacol, 54, 647-54.

Strassburg CP, Nguyen N, Manns MP, Tukey RH (1999b). UDPglucuronosyltransferase activity in human liver and colon. Gastroenterol, 116, 149-60.

Strassburg CP, Oldhafer K, Manns MP, Tukey RH (1997). Differential expression of the UGT1A locus in human liver, biliary and gastric tissue. Identification of UGT1A7 and 
UGT1A10 transcripts in extrahepatic tissue. Mol Pharmacol, 52, 212-20.

Strassburg CP,Strassburg A, Kneip S, et al (2002b). Developmental aspects of human hepatic drug glucuronidation in young children and adults. Gut, 50, 259-65.

Strassburg CP, Strassburg A, Nguyen N, et al (1999a). Regulation and function of family 1 and family 2 UDPglucuronosyltransferase genes (UGT1A, UGT2B) in human oesophagus. Biochem J, 338, 489-98.

Strassburg CP, Vogel A, Kneip S, Tukey RH, Manns MP (2002a). Polymorphisms of the human UDP glucuronosyltransferase (UGT) 1 A7 gene in colorectal cancer. Gut, 50, 851-6.

Tang KS, Chiu HF, Chen HH, et al (2005). Link between colorectal cancer and polymorphisms in the uridinediphosphoglucuronosyltransferase 1A7 and 1A1 genes. World J Gastroenterol, 11, 3250-4.

Tukey RH, Strassburg CP (2000). Human UDPglucuronosyltransferases: metabolism, expression, and disease. Annu Rev Pharmacol Toxicol, 40, 581-616.

Verlaan M, Drenth JPH, Truninger K, et al (2005). Polymorphisms of UDPglucuronosyltransferase $1 \mathrm{~A} 7$ are not involved in pancreatic diseases. J Med Genet, 42, 62.

Vogel A, Kneip S, Barut A, et al (2001). Genetic link of hepatocellular carcinoma with polymorphisms of the UDPGlucuronosyltransferase UGT1A7 Gene. Gastroenterol, 121, 1136-44.

Wang M, Qi YY, Chen S, et al (2012). Expression of UDPglucuronosyltransferase $1 \mathrm{~A}$, nuclear factor erythroid-E2related factor 2 and Kelch-like ECH-associated protein 1 in colonic mucosa, adenoma and adenocarcinoma tissue. Oncol Lett, 4, 925-30.

Wang WJ, Qin SH, Zhang JW, et al (2014). Combination doxorubicin and interferon- $\alpha$ therapy stimulates immunogenicity of murine pancreatic cancer Panc02 cells via up-regulation of NKG2D ligands and MHC class I. Asian Pac J Cancer Prev, 15, 9667-72.

Wang M, Sun DF, Wang S, et al (2013). Polymorphic expression of UDP-glucuronosyltransferase UGTIA gene in human colorectal cancer. Plos One, 8, 57045.

Zahir S, Arjmand A, Kargar S, et al (2013). Incidence and trends of malignant and benign pancreatic lesions in Yazd, Iran between 2001 and 2011. Asian Pac J Cancer Prev, 14, 2631-5. 